\title{
Hind limb conformation has limited influence on claw load distribution in dairy cows
}

\author{
Karl Nuss, ${ }^{*}$ Michael Haessig, and Judith Mueller \\ Department of Farm Animals, University of Zurich, Zurich CH 8057, Switzerland
}

\begin{abstract}
The high prevalence of claw lesions in dairy cows necessitates the investigation and hopefully elimination of factors involved in the etiology and pathogenesis of these disorders. Indirect genetic selection for specific conformation traits in feet and legs has been evaluated as a means of improving claw health but to date has not been successful. Claw disorders are commonly discussed in context with unequal claw load, and thus this study was designed to investigate the relationship between hind limb conformation and the load exerted on the respective claws. A total of 36 cows were divided into 3 groups of 12 based on the presence of parallel, straight, and cow-hocked hind limb conformation. The vertical ground reaction forces, claw prints, and mean and maximum pressures under the claws were measured in these cows before and after claw trimming. The principal characteristic of all 3 conformation traits was a significantly higher load on the lateral claws compared with the medial claws, which was least severe in cow-hocked cows. After functional foot trimming, the claws of the cows with straight conformation tended to have the most pronounced disproportion between the loads of the paired claws. Considering that a significantly higher load on the lateral claws occurred with all 3 conformations, the potential for improvement of claw health by means of indirect genetic selection for specific hind limb traits appears limited.
\end{abstract}

Key words: dairy cow, hind limb, conformation, claw load

\section{INTRODUCTION}

The prevalence of claw lesions in modern dairy cows is currently considered to be unacceptably high in terms

Received December 8, 2019.

Accepted March 4, 2020.

*Corresponding author: karl.nuss@uzh.ch of welfare concerns and consumer expectations (Huxley and Green, 2010; Oberbauer et al., 2013; Heringstad et al., 2018; Randall et al., 2019). To reduce the prevalence of lesions and improve locomotion soundness, indirect genetic selection for limb conformation traits has been used for many years and has been coordinated globally. Currently, the World Holstein Friesian Federation (http://www.whff.info) has approved 4 of 18 standard traits for limb conformation, and the World SimmentalFleckvieh Federation (https://www.fleckscore.com) has identified 4 of 22 traits. Because of the high prevalence of lameness in dairy cows, genetic selection for claw health has been increasingly promoted in breeding programs (Chapinal et al., 2013; van der Spek et al., 2015). Genetic traits that have been recently considered for feet and legs include the rear legs rear view, the rear legs side view, the foot angle, the heel depth, and locomotion (van der Waaij et al., 2005). Genetic evaluation of direct claw health has been implemented in the Netherlands and Scandinavian countries (Heringstad et al., 2018). Linear assessment of traits for feet and legs has been used for many years, yet the prevalence of claw diseases has increased considerably in the last decades.

Some conformation traits, including rear legs rear view and low foot angle, have been linked to clinical lameness along with cow-hocked and sickle-hocked conformations (Boettcher et al., 1998; Chapinal et al., 2013). Interestingly, cows with hind legs that appeared more parallel when viewed from the rear were genetically more (correlation: 0.39) predisposed to lameness (Ring et al., 2018).

Genetic correlations between hoof lesions and conformation traits were generally weak to moderate (Boettcher et al., 1998; Chapinal et al., 2013; Oberbauer et al., 2013; Schöpke et al., 2013). Other authors considered indirect selection using conformation traits for improving hoof health to be inefficient (Häggman and Juga, 2013; Ødegård et al., 2014, 2015; Heringstad et al., 2018). Rear legs side view, but not other foot and leg conformation traits, was a useful indicator trait to increase the accuracy of breeding values for claw 
health in genetic evaluation when used together with claw trimming information (Häggman et al., 2013). Heritability of commonly analyzed claw disorders based on data from routine claw trimming was generally low, with linear model estimates ranging from 0.01 to 0.14 (Heringstad et al., 2018). It was estimated that the prevalence of claw disorders could be reduced by no more than $0.7 \% / y r$ through selection for claw health (van der Linde et al., 2010).

An explanation for the low heritability of foot and leg traits or the low genetic correlation between conformation traits and claw health is lacking. A possible reason is that foot and leg conformation traits are indeed only weakly correlated with claw health. On the other hand, strong genetic correlations were found among sole hemorrhage, sole ulcer, and white line disease (Heringstad et al., 2018). These conditions have all been linked to abnormal weight bearing by the hind limb claws (Toussaint Raven, 1992; van der Tol et al., 2002; Nuss et al., 2019), which prompted us to investigate the relationship between hind limb conformation and the load acting on the claws. The goal of this study was to compare ground reaction forces exerted on claws, claw imprints, and pressures under the hind limb claws of cows with different hind limb conformations. Our hypothesis was that cows with parallel conformation have a more favorable load distribution between claws and claw zones than cows with cow-hocked or straight hind limb conformations.

\section{MATERIALS AND METHODS}

\section{Animals}

A total of 36 lactating, nonlame dairy cows aged $51.1 \pm 18.1$ mo (mean \pm standard deviation; range: 25-86 mo) were used. These included cows that had been referred to the medical or reproduction division of the Department of Farm Animals of the University of Zürich, Switzerland, and successfully treated for nonlife-threatening diseases (e.g., pneumonia, diseases of the teat; $\mathrm{n}=29$ ) as well as healthy cows from the research herd of the veterinary hospital $(n=7)$. The referred cows were to be discharged from the clinic and were no longer receiving pain medication. Owner consent was obtained before the trials, and the study was approved by the veterinary authorities of the Canton of Zurich, Switzerland (permission no. ZH 144/15). Breeds included Brown Swiss $(\mathrm{n}=14)$ and Holstein Friesian (n $=22$ ). Twenty cows were from freestall herds, and 16 were from tiestall herds. All cows were halter trained. Body weight was $637.2 \pm 74.6 \mathrm{~kg}$ (mean \pm standard deviation; range: $470-920 \mathrm{~kg}$ ). During the trial period, the cows were housed in tiestalls with a soft, $2.8-\mathrm{cm}$ thick rubber mat ("green mat" no. GM-R-28-12, GTA floor systems, Termen, Switzerland) and bedded with 10 to $15 \mathrm{~cm}$ of straw. The cows were fed hay, grass, corn silage, and minerals and had access to water ad libitum. All cows remained nonlame during the study and afterward returned safely to the herds of origin.

Cows with 3 different hind limb conformations were examined: parallel "rear legs rear view" (referred to as parallel conformation), "calcaneal tuber in" and "toes out" (referred to as cow-hocked), and straight "rear legs side view" (referred to as straight conformation; Figure 1). The hind limb conformation was assessed by 2 individuals (JM, KN) using visual criteria and according to the guidelines of breeders' associations (Tables 1 and 2; Figures 1 and 2) and measurements of the dorsal hock joint angle. In cows with parallel conformation, the metatarsus was vertical to the ground and the calcaneus and interdigital space were parallel to the longitudinal axis of the body (Figure 2). The hock angle was measured using a goniometer with 20-cm arms (Technocraft, Allchemet AG, Bäretswil, Switzerland) placed dorsally along the lower leg and metatarsus. The mean angle was calculated from 3 consecutive measurements. Cows with an angle $<168^{\circ}$ and parallel conformation were classified as parallel. Cows with cow-hocked conformation had medial rotation of the calcaneal tuber and lateral deviation of the interdigital space and a hock angle $>168^{\circ}$ (Table 1; Figure 2). Cows with straight conformation had a predominantly parallel conformation (Table 2) and a mean dorsal hock joint angle $>170^{\circ}$. The values of the vertical ground reaction force (vGRF), claw imprint area, and the mean and maximum pressures before and after foot trimming were compared among the 3 groups. Twelve cows were examined in each group. During the study period, 3 bow-legged cows were referred to our clinic, and their measurements were used for descriptive comparison only (Figure 2).

\section{Experimental Setup and Instrumentation}

The measuring system consisted of a force plate (type FP-9907-03-0007, AMTI, Watertown, MA) combined with a pressure plate (Footscan, RSscan International, Olen, Belgium), which was positioned on top of the force plate. The surface area of both plates was $108 \mathrm{~cm} \times 42 \mathrm{~cm}$, which was large enough to measure the weight load of the 2 hind limbs simultaneously. The pressure plate contained 8,192 pressure sensors as a 128 $\times 64$ matrix in a sensing area of $97.5 \mathrm{~cm} \times 32.5 \mathrm{~cm}$. A 
Table 1. Signalment, ground reaction force, and leg traits in 36 cows with different conformations (data of left and right hind limbs pooled; mean $\pm \mathrm{SD}$ )

\begin{tabular}{|c|c|c|c|}
\hline \multirow[b]{2}{*}{ Item } & \multicolumn{3}{|c|}{ Conformation $^{1}$} \\
\hline & Parallel & Cow-hocked & Straight \\
\hline Cows (no.) & 12 & 12 & 12 \\
\hline Age $(\mathrm{mo})$ & $54 \pm 22$ & $52 \pm 15$ & $47 \pm 18$ \\
\hline \multicolumn{4}{|l|}{ Body mass $(\mathrm{kg})$} \\
\hline Mean \pm SD & $633 \pm 61$ & $617 \pm 70$ & $662 \pm 90$ \\
\hline Minimum & 530 & 470 & 590 \\
\hline Maximum & 730 & 710 & 920 \\
\hline \multicolumn{4}{|c|}{ Ground reaction force on both hind limbs $(\mathrm{N})$} \\
\hline Before trimming & $2,831 \pm 298$ & $2,813 \pm 358$ & $3,039 \pm 403$ \\
\hline After trimming & $2,756 \pm 246$ & $2,758 \pm 370$ & $2,974 \pm 362$ \\
\hline \multicolumn{4}{|c|}{ Dorsal tarsal angle $\left(^{\circ}\right)$} \\
\hline Before trimming & $163 \pm 3$ & $164 \pm 3$ & $172 \pm 1$ \\
\hline After trimming & $165 \pm 3$ & $164 \pm 3$ & $172 \pm 1$ \\
\hline \multicolumn{4}{|c|}{ Dorsal fetlock angle $\left(^{\circ}\right)$} \\
\hline Before trimming & $164 \pm 4$ & $164 \pm 5$ & $161 \pm 5$ \\
\hline After trimming & $164 \pm 4$ & $164 \pm 6$ & $162 \pm 4$ \\
\hline
\end{tabular}

${ }^{1}$ Parallel $=$ calcaneus and interdigital spaces parallel or feet slightly toe-out; cow-hocked $=$ calcaneus rotated medially and feet toe-out; straight $=$ calcaneus and interdigital spaces parallel or feet toe-out.

single sensor had an active area of $0.762 \times 0.508 \mathrm{~cm}$, corresponding to a density of 2.6 sensors $\left./ \mathrm{cm}^{2}\right)$.

Each measurement lasted $5 \mathrm{~s}$ and with a sampling frequency of $100 \mathrm{~Hz}$ produced 500 single complete data sets of vGRF, claw imprint area, and mean and maximum pressures. Instrumentation, calibration process, and data acquisition were described in detail in a recent study (Nuss et al., 2019). The claw prints, the center of pressures for the 2 hind feet, and the vGRF of both hind limbs as well as changes in these variables during the measurement period were directly displayed on the computer screen. This allowed the operator to ensure that the weight distribution between the hind feet was even and that the cow did not move during the measurement. The measurement was repeated when the cows moved or the distribution of the load between the left and right limbs changed during the measurement. Footscan 7.7 Second Generation software (RSscan International) was used for data acquisition. The measurements were transferred to the Footscan balance 7.7 s Generation program (RSscan International) on a PC via an interface box and stored. The data were

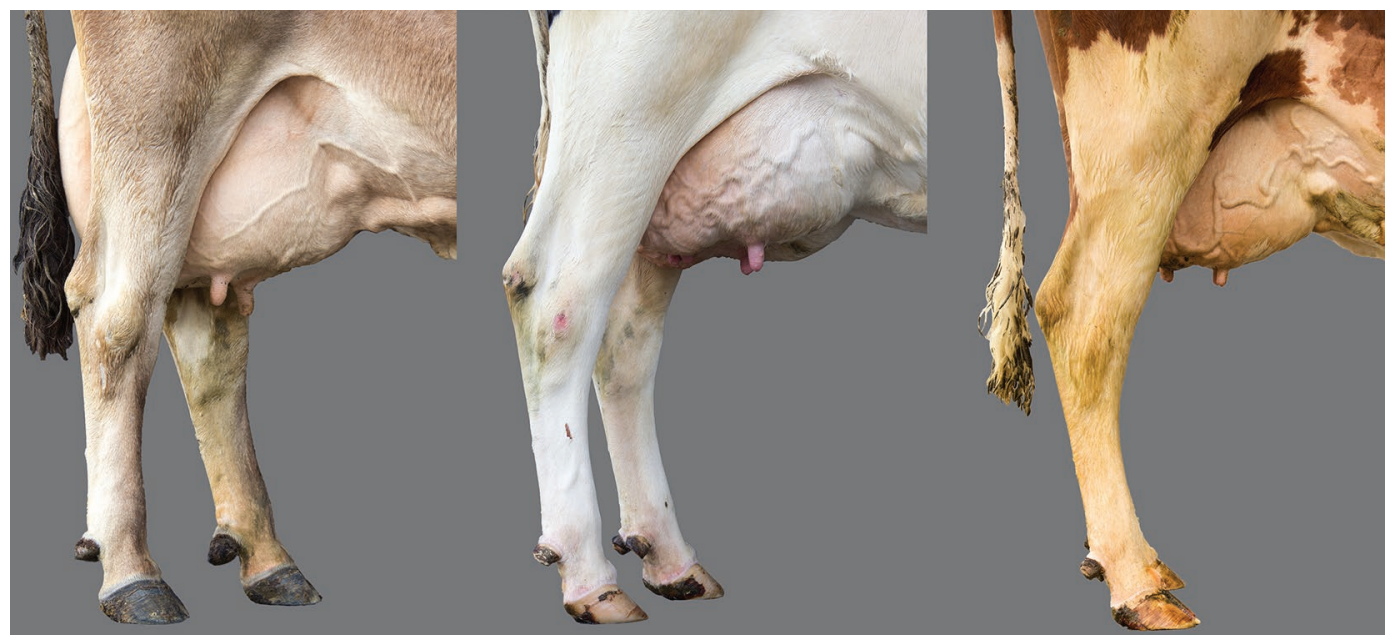

Figure 1. Cows with straight, intermediate, and slightly sickle-hocked hind limb conformation (from left to right) in the side view. These cows were graded by the authors as rear legs side view (rear legs set) 2, 5, and 7, respectively, according to the classification shown in Table 2 . 
Table 2. Limb conformation traits $^{1}$ (mean; range in parentheses) in 36 dairy cows with different conformations before and after trimming

\begin{tabular}{|c|c|c|c|c|}
\hline \multirow[b]{2}{*}{ Item } & \multirow[b]{2}{*}{ Optimal value } & \multicolumn{3}{|c|}{ Conformation $^{2}$} \\
\hline & & Parallel & Cow-hocked & Straight \\
\hline \multicolumn{5}{|l|}{ Pretrimming } \\
\hline Rear legs rear view ${ }^{3}$ & 9 & $7.6(7-9)$ & $4.6(3-6)$ & $7.3(3-9)$ \\
\hline Rear legs side view ${ }^{4}$ & 5 & $4.8(3-7)$ & $4.1(3-6)$ & $2.4(2-4)$ \\
\hline Foot angle $^{5}$ & 7 & $4.7(3-6)$ & $4.6(2-7)$ & $5.5(3-8)$ \\
\hline Hock development ${ }^{6}$ & 9 & $7.2(3-9)$ & $7.2(4-9)$ & $7.8(6-9)$ \\
\hline \multicolumn{5}{|l|}{ Posttrimming } \\
\hline Rear legs rear view ${ }^{3}$ & 9 & $7.4(6-9)$ & $5.3(3-8)$ & $7.3(6-8)$ \\
\hline Rear legs side view ${ }^{4}$ & 5 & $4.7(3-6)$ & $4.6(3-7)$ & $2.4(2-4)$ \\
\hline Foot angle $^{5}$ & 7 & $5.2(2-8)$ & $5.6(3-8)$ & $6.5(4-8)$ \\
\hline
\end{tabular}

${ }^{1}$ Recorded according to guidelines by ICAR (2015), World Holstein Friesian Federation (2020), World Simmental Fleckvieh Federation (2020), and Braunvieh Schweiz (2019).

${ }^{2}$ Parallel $=$ calcaneus and interdigital spaces parallel or feet slightly toe-out; cow-hocked $=$ calcaneus rotated medially and feet toe-out; straight $=$ calcaneus and interdigital spaces parallel or feet toe-out.

${ }^{3} 1=$ extreme hock in, $9=$ parallel.

${ }^{4} 1=$ straight, $5=$ intermediate, $9=$ sickle-hocked.

${ }^{5} 1=$ very low, $5=$ intermediate, $9=$ very steep.

${ }^{6} 1=$ a lot of fluid, $5=$ intermediate, $9=$ clean and dry.

then imported into an Excel (Microsoft Corp., Redmond, WA) file and analyzed with SPSS (IBM SPSS Statistics, Version 23, IBM, Armonk, NY).

\section{Experimental Protocol}

Before the measurements were made, the cows were scored for lameness and only those with a lameness score of $0 / 5(0=$ no signs of lameness, 1 mild lameness, $5=$ severe lameness/non-weight-bearing in one limb) were included in the study. A pressure washer was used to clean the cows before hind limb conformation was assessed, and the legs were photographed from the side and from behind under standardized conditions. Pictures were taken in raw format with a Canon EOS 600D camera (Canon, Tokyo, Japan) using a focal length of $50 \mathrm{~mm}$, an aperture setting of $\mathrm{f} / 8.0$ to 11.0 , an ISO of 400 , a shutter speed of $1 / 100$ to $1 / 125 \mathrm{~s}$, and a distance of $3 \mathrm{~m}$ from the calcaneus. A laser distance-measuring device (Bosch Zamo Typ 0603672400, Robert Bosch

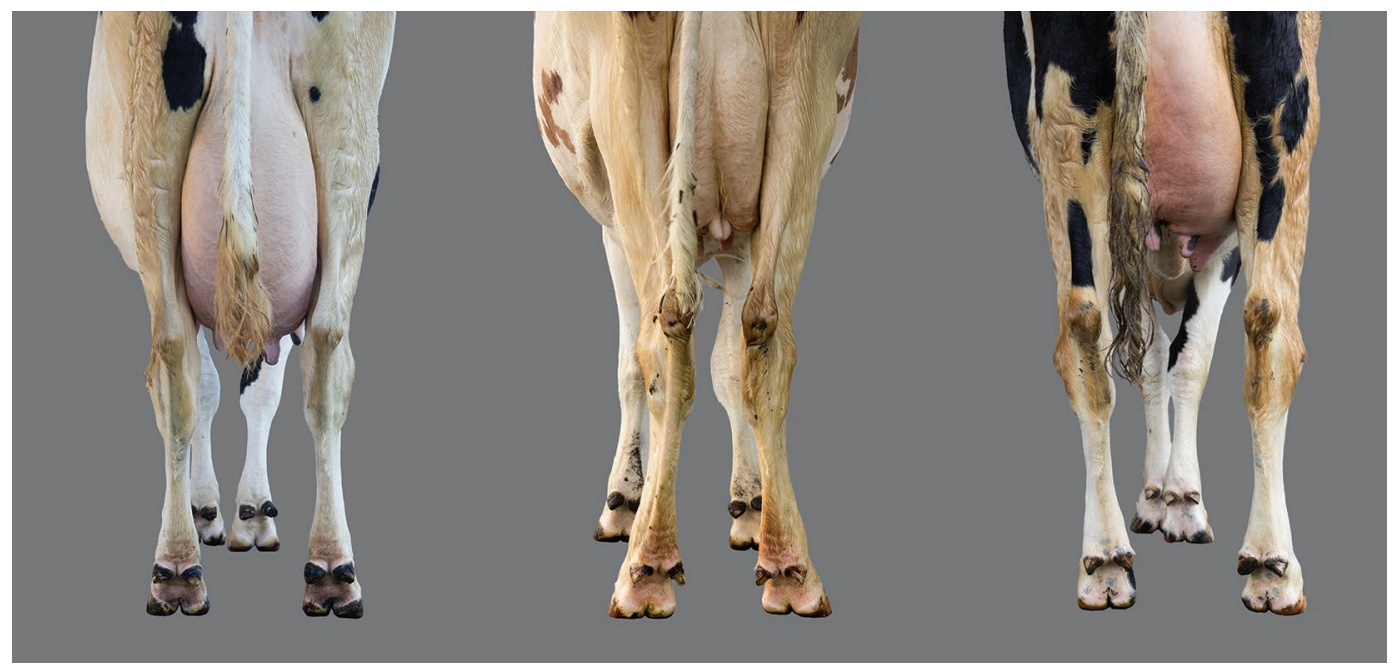

Figure 2. Hind limb conformations in the rear legs rear view: cows with parallel (left), cow-hocked (middle), and bow-legged (right) hind limb conformations. These cows were graded by the authors as rear legs rear view 7, 4, and $>9$, respectively, according to the classification shown in Table 2. 
GmbH, Stuttgart, Germany) was used to maintain a constant distance. A level built into the head plate of the tripod was used to ensure a horizontal camera position. To simplify and standardize processing of the photos in Photoshop CS5 (Adobe, San Jose, CA), all photos were taken with the cows standing on the same level surface (Figures 1 and 2) against a monochrome wall. The cows were then led onto the measuring platform, and 3 consecutive measurements of the claw load distribution were made; short time intervals between measurements allowed for repositioning of the feet. Thereafter, the hind limb claws were trimmed by the authors according to the principles of Toussaint Raven (1992) using a modified approach regardless of hind limb conformation (https://tube.switch.ch/cast/ videos/072fd51f-7e09-43bd-bd19-0359e370f3a0). The front claws were trimmed at the same time if required. Foot trimming had been done a mean of 5.2 mo (median: 6; range: 1-12) before the start of the study, and therefore no claws were severely overgrown or unbalanced. Mild heel horn erosions or stage M1 and M3 digital dermatitis were treated with tetracycline spray and were tolerated for this study provided that they did not cause lameness before and after trimming. On the second measuring day, which was usually the following day, the cows were pressure washed and photographed again, and 3 consecutive measurements were made as previously described.

\section{Data Processing and Statistics}

Of the 3 serial measurements, the one with a distribution of vGRF between the hind feet closest to 50:50 was analyzed. A single data set was randomly picked from the selected serial measurements using Microsoft Excel Macros, and a custom-made Excel analysis worksheet was used to extract the relevant variables. By placing digital templates of claw shapes over the Excel sheet, the borders of the medial and lateral claws could be differentiated and the claws were divided into a sole zone and a heel zone. The claw imprints were not concise enough to allow for a more detailed division into more than 2 zones. Finally, all extracted variables - vGRF $(\mathrm{N})$, the imprint of the claw soles on the ground $\left(\mathrm{cm}^{2}\right)$, the mean pressure $(\mathrm{kPa})$, and the maximum pressure $(\mathrm{kPa})$ - were analyzed statistically.

Data for the right and left hind limbs were pooled and subjected to exploratory data analysis. In addition, percentages were calculated for the distributions of the vGRF between the paired claws and between the heel zones and sole zones of individual claws as well as the means for these percentages (Table 3). The Shapiro-Wilk test was used to test the data for normality. Normally distributed data were compared using a

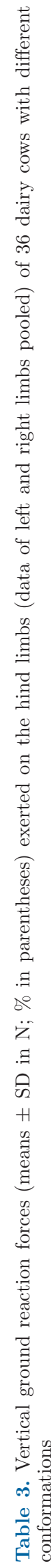
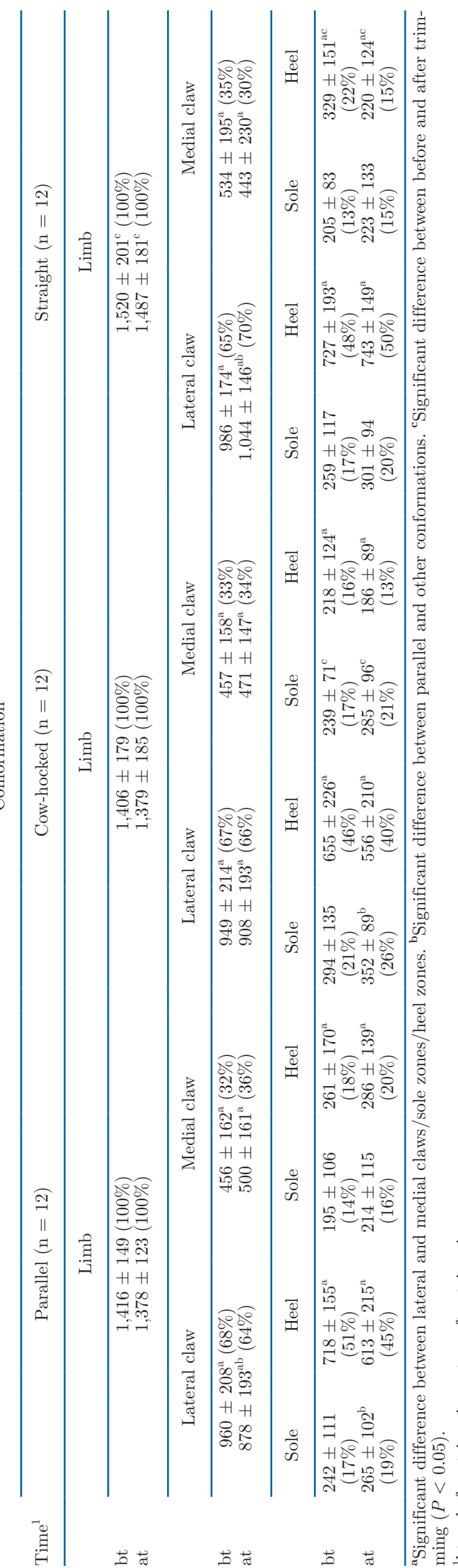

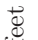

$\stackrel{0}{\longleftarrow}$

$\stackrel{\vec{\vartheta}}{\rightleftharpoons}$

这

远 
paired $t$-test, and not-normally distributed data were compared using the Wilcoxon signed-rank test. Differences between data from cows with parallel conformation and data from cows with cow-hocked and straight conformation were analyzed using the Mann-Whitney $\mathrm{U}$ test. Differences were considered significant at $P \leq$ 0.05 .

\section{RESULTS}

\section{Cows with Parallel Hind Limb Rear View Conformation}

After foot trimming, the angle of the hock was slightly larger than before trimming, but the angle of the fetlock did not change. The weight measured in the hind limbs was smaller after trimming than before. This was considered an artifact caused by stress, decreased feed intake, and an increase in defecation during the measuring procedure.

Before trimming, the mean vGRF of the pooled hind limb measurements of the lateral claw was significantly greater than that of the medial claw $(68 \%: 32 \%$, Table $3)$. The heel zone of the lateral claw bore $51 \%$ of the weight of the entire limb, the heel zone of the medial claw $18 \%$, the sole zone of the lateral claw $17 \%$, and the sole zone of the medial claw $14 \%$. The proportion of the vGRF of the lateral claw was numerically smaller after trimming than before trimming ( $64 \%$ vs. $68 \%$ of the vGRF of the entire limb). Trimming significantly reduced the vGRF of the heel zone of the lateral claw from $51 \%$ to $45 \%$ of the entire limb load.

Before trimming, the mean total claw print of the pooled hind limb measurements was $82.4 \pm 8.2 \mathrm{~cm}^{2}$. The mean print of the heel zone of the lateral claw was significantly larger than that of the sole zone of the same claw or the zones of the medial claw (Table 4). Trimming resulted in a significant decrease in the print of the heel zone of the lateral claw. The prints of the heel and sole zones of the medial claw were increased after trimming but remained significantly smaller than the corresponding prints of the lateral claw (Table 4).

Before trimming, the mean pressure under the hind feet of cows with parallel conformation was $174 \pm 24$ $\mathrm{kPa}$. The mean pressure under the lateral claw was significantly higher than that under the medial claw. A maximum mean pressure of $242 \pm 43 \mathrm{kPa}$ was recorded under the heel zone of the lateral claw (Table 5); this pressure was significantly higher than that of the ipsilateral sole zone and of both claw zones of the medial claw. Trimming resulted in a decrease in mean pressure under the lateral claw, an increase in pressure under the medial claw, and elimination of the significant difference between the pressures under the paired claws. The

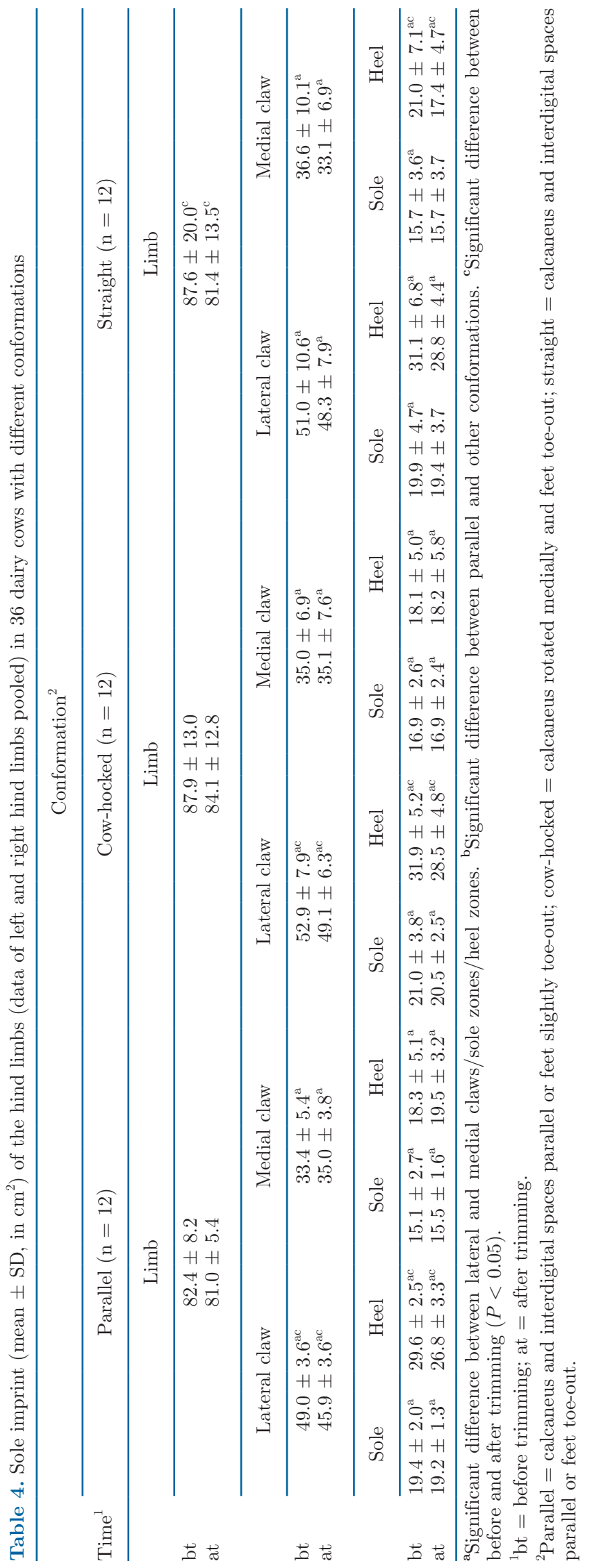



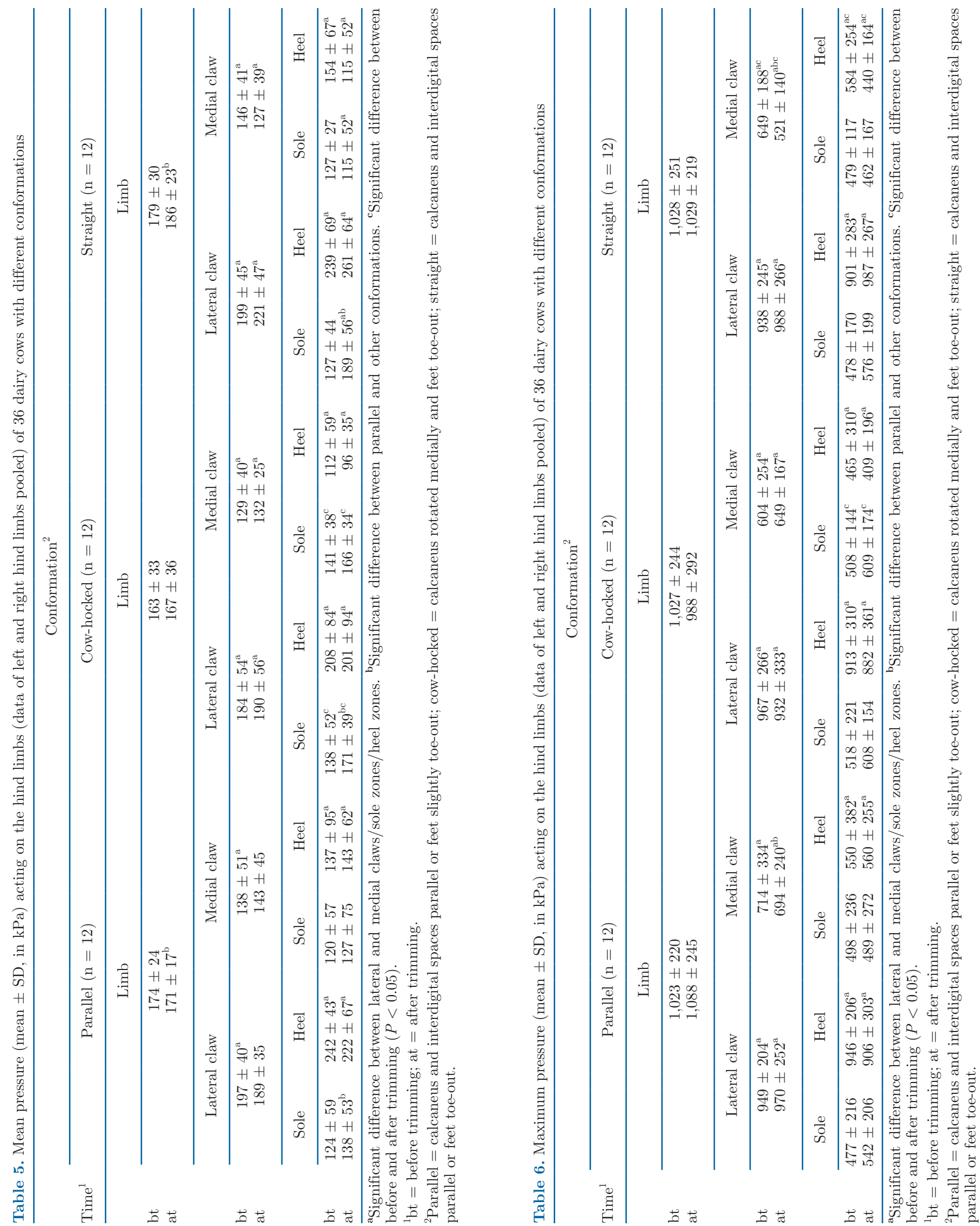
mean pressure under the heel zone of the lateral claw was lower after trimming, which was accompanied by mild numerical increases in pressure in the other zones, but it remained significantly higher than the pressure under the heel zone of the medial claw.

The maximum pressure under the hind feet was 1,023 $\pm 220 \mathrm{kPa}$ (Table 6 ). The maximum pressure under the lateral claw was significantly higher than that under the medial claw $(949 \pm 204 \mathrm{kPa}$ vs. $714 \pm 334 \mathrm{kPa})$. On average, the maximum pressure under the heel zone of the lateral claw was almost twice that of the sole zone of the same claw and the zones of the medial claw (Table 6). Trimming resulted in a small numerical increase in maximum pressure under the lateral claw, and the reduction in maximum pressure of the heel zone of the lateral claw obtained through trimming was slight and not significant (Table 6).

The data from the cows with cow-hocked and straight conformation were analyzed according to the cows with parallel conformation (Tables 3-6). The main differences between cows with parallel conformation and those with cow-hocked and straight conformation are described here.

\section{Comparison of Cows with Parallel and Cow-Hocked Conformation}

Before trimming, the distribution of the vGRF exerted on the lateral and medial claws did not differ significantly between the 2 groups (Table 3 ), and cows of both groups had a much higher load on the lateral claw of similar proportion. However, the proportion of the entire load of the limb borne by the sole zone of the lateral claw was slightly greater in cow-hocked cows than in cows with parallel conformation (means of percentages of the entire vGRF borne by sole zone: $21 \%$ vs. $17 \%$ ). The same applied to the medial claw with respective percentages of $17 \%$ and $14 \%$. After functional trimming, the proportional load of the sole zone of the lateral claw was $26 \%$ in cow-hocked cows and $19 \%$ in cows with parallel conformation. The proportional load of the heel zone of the lateral claw was reduced from $46 \%$ to $40 \%$ of the entire limb load but remained the greatest vGRF of all zones and was significantly greater than the load of the heel zone of the medial claw. The sole zone of the medial claw of cow-hocked cows had a numerically greater proportional load after trimming compared with cows with parallel conformation $(21 \%$ vs. $16 \%$ ). In summary, functional trimming in cowhocked cows resulted in a shift of weight bearing from the heel zones to the sole zones.

Before trimming, cow-hocked cows had larger combined claw prints than cows with parallel conformation, and functional trimming resulted in a slightly larger relative decrease as well as an absolute decrease in claw print area in cow-hocked cows. The decrease was significant for the lateral claw and its heel zone in cows with parallel conformation and in cow-hocked cows (Table 4).

Before trimming, the mean pressures under the claws and their heel zones were lower in cow-hocked cows than in cows with parallel conformation (Table 5). Mean and maximum pressures under the heel zones of cow-hocked cows decreased further with foot trimming, and the mean pressure under the sole zone of the lateral claw became significantly higher in cow-hocked cows than in cows with parallel conformation.

\section{Comparison of Cows with Parallel and Straight Conformation}

Before trimming, the proportional loads of the legs, claws, and claw zones did not differ significantly between the 2 groups. The proportional load of the heel zone of the medial claw of cows with straight conformation tended to be greater than that of cows with parallel conformation (Table 3). In cows with straight conformation, trimming resulted in a shift of load toward the lateral claw and its heel zone, whereas in cows with parallel conformation, the desired effect of shifting of load to the medial claw was observed. The combined claw print area was greater in cows with straight conformation than in cows with parallel conformation before trimming but was equal in both groups after trimming (Table 4). After trimming, the mean pressure under a hind limb was significantly higher in cows with straight conformation than in cows with parallel conformation (Table 5). Likewise, the mean and maximum pressures under the heel zone of the lateral claw were increased after trimming, whereas the pressures were decreased in cows with parallel conformation. The maximum pressure under the medial claw decreased in both groups, but the decrease was significant only in cows with straight conformation. In cows with straight conformation, the maximum pressures under the heel zone of the medial claw differed significantly before and after trimming (Table 6).

\section{Comparison of Cows with Parallel and Bow-Legged Conformations}

In bow-legged cows, weight bearing between paired hind claws was considerably more asymmetric at the expense of the lateral claw than in the other groups. Before trimming, the proportions of the vGRF of the lateral and medial claws were $82 \%$ and $18 \%$ (means 
of proportional vGRF, parallel conformation: $68 \%$ and $32 \%$ ). Bow-legged cows had a higher mean pressure under the feet than cows of the other groups because the claw prints were relatively small both before and after trimming. This was particularly true for the mean pressure under the lateral claw and its heel zone, which were considerably higher than those in cows with parallel conformation. The same was valid for the mean maximum pressure under the feet, the lateral claw, and its heel zone. These maximum pressures were even higher after trimming.

\section{DISCUSSION}

The main goal of this study was to investigate the effect of hind limb conformation on claw load in dairy cows. To our surprise, before functional trimming, there were no significant differences in vGRF, claw print area, and mean and maximum pressures of the hind feet of cows with parallel, cow-hocked, and straight conformation. This means that regardless of conformation, the distribution of weight between the lateral and medial claws of a hind foot was unequal. Cows of all 3 groups had significant asymmetry in load distribution between the paired claws with a pronounced higher load on the lateral claw (65-68\% of the vGRF of the pooled hind limbs) and its heel zone (46-51\% of the vGRF) compared with the medial claw and its heel zone. In all 3 conformation groups, the heel zone of the lateral claw was the zone with the highest vGRF and the greatest mean and maximum pressures. This means that none of the 3 conformations were characterized by a balanced load of the paired claws. The adverse effects of this load asymmetry and the high load on the lateral hind claw including its heel zone are obvious (Toussaint Raven, 1973; van der Tol et al., 2002; Nuss et al., 2019). The uniformity of asymmetric load distribution in the hind feet of dairy cows regardless of conformation is a possible explanation for the previous failure to improve claw health by means of indirect genetic selection for certain hind limb conformation traits (Häggman and Juga, 2013; Häggman et al., 2013; Ødegård et al., 2013, 2014, 2015).

Our method of functional trimming resulted in 6 significant differences between cows with parallel conformation and cows of the other 2 groups; however, the significantly higher load on the lateral claw compared with the medial claw remained a feature in all 3 groups. This means that our method of trimming was insufficient to balance the loads on the paired hind claws even though, according to our assessment, the soles of the paired claws were level after trimming. Therefore, offloading of the lateral claw on hard ground may not be feasible unless an excessive amount of sole can be paired off safely from the lateral claw.

Interestingly, the heel zone of the lateral claw of cowhocked cows bore less weight after trimming compared with cows with parallel or straight conformation; cowhocked cows bore significantly more weight on the sole zone of the lateral claw than cows with parallel conformation. Cow-hocked cows have a genetic predisposition for hind limb lameness because the wide hind-leg stance is thought to lead to a vicious circle of lateral claw stress and claw horn hypertrophy, aggravating the original problem of excessive load on the lateral claw (Boettcher et al., 1998; Capion et al., 2008; Chapinal et al., 2013). Our data refute the notion that the relatively higher load on the lateral hind claw is exacerbated by cowhocked conformation; on the contrary, the heel zone of cow-hocked cows bore less weight compared with cows of the other 2 groups. This supports the opinion that cow-hocked conformation tends to offload the lateral claw (Toussaint Raven, 1973). Based on these observations and considering that a large proportion (81\%) of heifers were shown to have a wide-based stance with the hocks together and lateral rotation of the feet before calving (Capion et al., 2008), it is conceivable that cow-hocked conformation, like parallel conformation, is part of the normal variation in dairy cow conformation, provided that it is not severe.

On the other hand, in cows with straight conformation, functional trimming led to increased weight bearing in the lateral claw, which bore a relatively small load before trimming. Furthermore, the mean pressure under the limb after trimming was significantly higher compared with cows with parallel conformation. The maximum pressure under the medial claw in cows with parallel conformation was significantly higher after trimming than in cows with straight conformation. Thus, with respect to the unequal load distribution between the lateral and medial claws after functional trimming, straight conformation was the least favorable. Trimming of cows with straight conformation may therefore require special measures, such as removing less sole horn from the medial claw and more from the lateral claw compared with cows with parallel or cowhocked conformation. The highest load on the lateral claw occurred in bow-legged cows, which renders this conformation the least favorable with respect to claw health.

The angles at the front of the hock were in agreement with values of $167.3+0.7^{\circ}$ (range: $154.3-177.4^{\circ}$ ) reported for Holstein heifers (Vermunt and Greenough, 1996). At the time of that study, there was a tendency to select dairy heifers with moderately straight hind limbs. However, problems associated with this confor- 
mation include reduced shock absorption by soft tissue structures, leading to increased force on skeletal structures and degenerative joint disease (Vermunt and Greenough, 1996). In the present study, cows with dorsal hock joint angles $>170^{\circ}$ were considered to have straight conformation. Foot trimming tended to increase the angle and resulted in a load distribution between the lateral and medial claws that was less favorable than in cows with cow-hocked or parallel conformation. For good claw and leg health in dairy cows, we believe that it is counterproductive to select for dorsal hock angles greater than $170^{\circ}$. However, other authors have proposed different critical angles for the hock joint (Fessl, 1974; Herlin and Drevemo, 1997), and therefore it would make sense to quantify the linear evaluation of tarsal angles to facilitate verification of this trait in the field.

The dorsal fetlock angle of 164 to $165^{\circ}$ measured in cows with parallel conformation was largely in agreement with the range of 154 to $162^{\circ}$ reported by Fessl (1974) and of 162 to $171^{\circ}$ reported by Herlin and Drevemo (1997). In our study, the angles did not differ significantly among the 3 groups or before and after foot trimming.

\section{CONCLUSIONS}

The significant unequal load distribution between the lateral and medial claws of the hind limbs did not differ among cows with parallel, straight, and cow-hocked conformation. This observation helps explain why genetic correlations between hoof lesions and hind limb conformation traits calculated thus far have been only weak to moderate. The potential to alleviate the high load exerted on the lateral claws by means of genetic selection appears to be limited. Therefore, prophylaxis of traumatic claw lesions should focus on optimization of barn flooring and cubicle design. Cow-hocked conformation was associated with offloading of the heel zone of the lateral claw.

\section{ACKNOWLEDGMENTS}

The Cantonal University of Zurich is thanked for financing the study. Rudi Waelchli and Chris Winder are thanked for comments and translation. The authors state that they have no conflicts of interest.

\section{REFERENCES}

Boettcher, P. J., J. C. Dekkers, L. D. Warnick, and S. J. Wells. 1998. Genetic analysis of clinical lameness in dairy cattle. J. Dairy Sci. 81:1148-1156. https://doi.org/10.3168/jds.S0022-0302(98)75677 $-2$.
Schweiz, B. 2019. Broschuere Exterieurbeurteilung. Accessed Apr. 22, 2020. https://homepage.braunvieh.ch/xml_1/internet/de/ application/d126/f1322.cfm?braunvieh=exterieurbeurteilung.

Capion, N., S. M. Thamsborg, and C. Enevoldsen. 2008. Conformation of hind legs and lameness in Danish Holstein heifers. J. Dairy Sci. 91:2089-2097. https://doi.org/10.3168/jds.2006-457.

Chapinal, N., A. Koeck, A. Sewalem, D. F. Kelton, S. Mason, G. Cramer, and F. Miglior. 2013. Genetic parameters for hoof lesions and their relationship with feet and leg traits in Canadian Holstein cows. J. Dairy Sci. 96:2596-2604. https://doi.org/10.3168/jds.2012 $-6071$.

Fessl, L. 1974. Activity of joints in cattle during walking. A contribution to movement analysis in cattle. Deutsche tierarztliche Wochenschrift 81:129-132.

Häggman, J., and J. Juga. 2013. Genetic parameters for hoof disorders and feet and leg conformation traits in Finnish Holstein cows. J. Dairy Sci. 96:3319-3325. https://doi.org/10.3168/jds.2012-6334.

Häggman, J., J. Juga, M. J. Sillanpaa, and R. Thompson. 2013. Genetic parameters for claw health and feet and leg conformation traits in Finnish Ayrshire cows. J. Anim. Breed. Genet. 130:89-97. https://doi.org/10.1111/j.1439-0388.2012.01007.x.

Heringstad, B., C. Egger-Danner, N. Charfeddine, J. E. Pryce, K. F. Stock, J. Kofler, A. M. Sogstad, M. Holzhauer, A. Fiedler, K. Müller, P. Nielsen, G. Thomas, N. Gengler, G. de Jong, C. Ødegård, F. Malchiodi, F. Miglior, M. Alsaaod, and J. B. Cole. 2018. Invited review: Genetics and claw health: Opportunities to enhance claw health by genetic selection. J. Dairy Sci. 101:4801-4821. https:// doi.org/10.3168/jds.2017-13531.

Herlin, A. H., and S. Drevemo. 1997. Investigating locomotion of dairy cows by use of high speed cinematography. Equine Vet. J. 29(Suppl.):106-109. https://doi.org/10.1111/j.2042-3306.1997.tb05066.x.

Huxley, J., and M. Green. 2010. More for less: Dairy production in the 21st century. Vet. Rec. 167:712-713. https://doi.org/10.1136/ vr.c5676.

ICAR (International Committee for Animal Recording). 2015. Conformation recording dairy and beef cattle. Accessed Mar. 2 2020. https://www.icar.org/wp-content/uploads/2015/08/ Conformation-Recording-CR-WG.pdf.

Nuss, K., J. Muller, and T. Wiestner. 2019. Effects of induced weight shift in the hind limbs on claw loads in dairy cows. J. Dairy Sci. 102:6431-6441. https://doi.org/10.3168/jds.2018-15539.

Oberbauer, A. M., S. L. Berry, J. M. Belanger, R. M. McGoldrick, J. M. Pinos-Rodriquez, and T. R. Famula. 2013. Determining the heritable component of dairy cattle foot lesions. J. Dairy Sci. 96:605-613. https://doi.org/10.3168/jds.2012-5485.

Ødegård, C., M. Svendsen, and B. Heringstad. 2013. Genetic analyses of claw health in Norwegian Red cows. J. Dairy Sci. 96:7274-7283. https://doi.org/10.3168/jds.2012-6509.

Ødegård, C., M. Svendsen, and B. Heringstad. 2014. Genetic correlations between claw health and feet and leg conformation in Norwegian Red cows. J. Dairy Sci. 97:4522-4529. https://doi.org/10 $.3168 /$ jds.2013-7837.

Ødegård, C., M. Svendsen, and B. Heringstad. 2015. Foot and leg conformation traits have a small effect on genomic predictions of claw disorders in Norwegian Red cows. J. Dairy Sci. 98:4139-4147. https://doi.org/10.3168/jds.2014-9186.

Randall, L. V., H. J. Thomas, J. G. Remnant, N. J. Bollard, and J. N. Huxley. 2019. Lameness prevalence in a random sample of UK dairy herds. Vet. Rec. 184:350. https://doi.org/10.1136/vr.105047.

Ring, S. C., A. J. Twomey, N. Byrne, M. M. Kelleher, T. Pabiou, M. L. Doherty, and D. P. Berry. 2018. Genetic selection for hoof health traits and cow mobility scores can accelerate the rate of genetic gain in producer-scored lameness in dairy cows. J. Dairy Sci. 101:10034-10047. https://doi.org/10.3168/jds.2018-15009.

Schöpke, K., S. Weidling, R. Pijl, and H. H. Swalve. 2013. Relationships between bovine hoof disorders, body condition traits, and test-day yields. J. Dairy Sci. 96:679-689. https://doi.org/10.3168/ jds.2012-5728.

Toussaint Raven, E. 1973. Determining of weight-bearing by the bovine foot. Neth. J. Vet. Sci. 5:99-103. 
Toussaint Raven, E. 1992. Cattle footcare and claw trimming. 3rd impression, with amendments. Farming Press, Ipswich, UK.

van der Linde, C., G. de Jong, E. P. Koenen, and H. Eding. 2010. Claw health index for Dutch dairy cattle based on claw trimming and conformation data. J. Dairy Sci. 93:4883-4891. https://doi.org/10 .3168/jds.2010-3183.

van der Spek, D., J. A. van Arendonk, and H. Bovenhuis. 2015. Genome-wide association study for claw disorders and trimming status in dairy cattle. J. Dairy Sci. 98:1286-1295. https://doi.org/10 $.3168 /$ jds.2014-8302.

van der Tol, P. P., J. H. Metz, E. N. Noordhuizen-Stassen, W. Back, C. R. Braam, and W. A. Weijs. 2002. The pressure distribution under the bovine claw during square standing on a flat substrate. J. Dairy Sci. 85:1476-1481. https://doi.org/10.3168/jds.S0022 $-0302(02) 74216-1$ van der Waaij, E. H., M. Holzhauer, E. Ellen, C. Kamphuis, and G. de Jong. 2005. Genetic parameters for claw disorders in Dutch dairy cattle and correlations with conformation traits. J. Dairy Sci. 88:3672-3678. https://doi.org/10.3168/jds.S0022-0302(05)73053 -8 .

Vermunt, J. J., and P. R. Greenough. 1996. Hock angles of dairy heifers in two management systems. Br. Vet. J. 152:237-242. https:// doi.org/10.1016/S0007-1935(96)80077-7.

World Holstein Friesian Federation. 2020. Linear type diagrams. Accessed Mar. 3, 2020. http://www.whff.info/documentation/ typeharmonisation.php\#go1.

World Simmental Fleckvieh Federation. 2020. Fleckscore. Accessed Mar. 2, 2020. https://www.fleckscore.com/en/traits/calculation-of -total-scores/feet-and-legs/. 